\title{
On the use of diatom-based biological monitoring Part 2: A comparison of the response of SASS 5 and diatom indices to water quality and habitat variation
}

\author{
PA de la Rey ${ }^{1 *}, \mathrm{H}_{\text {Roux }}{ }^{2}, \mathrm{~L}$ van Rensburg ${ }^{1}$ and $A$ Vosloo $^{3}$ \\ ${ }^{1}$ School for Environmental Science and Development, North-West University, Potchefstroom, South Africa \\ ${ }^{2}$ Department of Agriculture Conservation and Environment, North West Province, South Africa \\ ${ }^{3}$ School of Biological and Conservation Science, University of KwaZulu-Natal, Durban, South Africa
}

\begin{abstract}
Due to the fact that South Africa is a water-scarce country, integrated water resource management based on sound information is essential. Bio-indicators have provided valuable information for water resource management in recent years and have enjoyed increasing popularity. Bio-indicators especially stepped to the forefront with the realisation that aquatic eco-systems are not only a source of water but also deliver several goods and services, as well as being essential for industrial growth and quality of life of many South Africans. This study aimed to quantitatively test two kinds of biomonitoring tools namely diatom-based (SPI and BDI) and macro-invertebrate based (SASS 5) in order to assess their applicability in South African River systems; and whether any additional information can be gained by using the two tools in tandem. The results showed that diatom indices are affected more by changes in water quality than SASS 5, while SASS 5 displayed a higher dependency on habitat quality, as measured by IHAS, than the diatom indices. It is therefore suggested that the two indices be utilised as complementary indicators for integrated assessment of river health.
\end{abstract}

Keywords: diatoms; Bacillariophyceae; bioindicators; SASS 5; species diversity indices; water quality

\section{Introduction}

Species of flora and fauna present in riverine ecosystems reflect both the present and past history of the water quality at a particular point in the river, allowing detection of disturbances that might otherwise be missed (Eekhout et al., 1996). Aquatic communities (e.g. fish, riparian vegetation, macro-invertebrates) can integrate and reflect the effects of chemical and physical disturbances that occur in river ecosystems over extended periods of time.

Walmsley et al. (2000) stated that bio-indicators are ideal means of monitoring aquatic ecosystems, leading towards integrated water resource management, and that bio-indicators provide a summary of conditions 'rather like temperature and blood pressure are used to measure human health'.

The South African Department of Water Affairs and Forestry (DWAF), as custodians of the water resources of the country, initiated the development of a National Aquatic Ecosystem Biomonitoring Programme (also called the River Health Programme or RHP) during 1995 (Roux, 1997). Examples of such indicators include the Fish Assemblage Integrity Index (Kleynhans, 1999), the Riparian Vegetation Index (Kemper, 2001) as well as the South African Scoring System, better known as SASS (Chutter, 1998). Although some methods have been available for many years, biomonitoring has only recently become a routine tool in the management of South Africa's inland waters (Davies and Day, 1998). The SASS biomonitoring system has

* To whom all correspondence should be addressed.

Alternative address: Africa Geo-Environmental Services, PO Box 19460, Potchefstroom 2522, South Africa

面 +27 18297 6588; fax: +27 18297 4813;

e-mail: adelarey@ages-group.com

Received 30 October 2006; accepted in revised form 28 November2007. gained a large body of support as a rapid and fairly accurate system of evaluating water quality in streams and rivers, and is currently in its $5^{\text {th }}$ revised form namely SASS 5 (Dickens and Graham, 2002).

Recently diatom-based indices such as the Specific Pollution Index (SPI) and Biological Diatom Index (BDI) have come into the spotlight as potential additions to more established bio-indicators such as SASS 5. Several papers have been published in the past few years exploring the potential use of diatoms as bioindicators such as Taylor et al. (2007b), De la Rey et al. (2004) and Harding et al. (2005). A standard protocol for assessment using diatoms has also been published (Taylor et al., 2005) to facilitate comparability of diatom index results. The value of diatoms as indicators has been recognised to the point that it has been included in the state of the rivers report for the Crocodile (West) - Marico River Water Management Area (Taylor et al., 2007c; River Health Programme, 2005).

In a recently published article, Ashton et al. (2005) called for a shift in thinking from a point where water is seen as simply a commodity to recognising that it is an integral part of a larger ecosystem, and that such an ecosystem approach demands an understanding of the various components of the hydrological cycle as well as the inter-relationships of these various components. For this reason it is believed important to understand how different bio-indicators respond to the various changes in the aquatic ecosystem.

With the above-mentioned in mind, it is also important to evaluate biological indices in terms of their relationship to habitat characteristics. In this study, the Integrated Habitat Assessment System: Version 2 (McMillan, 1998) was used as indicator of habitat condition. This assessment focuses on sampling habitat, especially habitat that can be utilised by invertebrate fauna, as well as other stream characteristics, such as water quality, which may be modified by anthropogenic or natural impacts. 
This paper represents the second part of a study that aims to evaluate the efficacy of diatom-based indices in river systems in South Africa. The paper follows from Part 1 (De la Rey et al., 2008) which concluded that aut-ecological indices should be preferentially used as they respond in a linear fashion to environmental water quality gradients.

Part 2 of this paper aims to compare the relationship of the SASS 5 invertebrate index and diatom indices to chemical water quality and habitat availability. There are several questions that the current paper strives to answer. Firstly whether there is a significant difference in the response of SASS 5 and diatom-based aut-ecological indices to changes in stream habitat and water quality. If the two indices respond similarly, and to the same extent, to water quality variables, there would be no additional benefit to be found in using both indices for monitoring changes and impacts in rivers. Secondly the present paper aims to evaluate the dependency of index response on variation in habitat and seasonal changes. The answers gained from such analysis can assist in the application and interpretation of results gained when using the various bio-indicators evaluated in this paper.

\section{Materials and methods}

\section{Sampling localities}

For information on the sampling localities please refer to Part 1 (De la Rey, 2008)

\section{Indices calculations}

Macroinvertebrates were collected using the SASS 5 methodology. The SASS score, Average Score per Taxon (ASPT) and Number of Taxa (No. of Taxa) were calculated according to standard methods as set out in Dickens \& Graham (2002) and Chutter (1998).

Diatoms were collected, prepared and enumerated according to the protocol as set out in Taylor et al. (2005). The diatom identification was according to the nomenclature of Krammer and Lange Bertalot (1986-1991). For the current paper the autecological method for evaluating water quality by means of diatoms were used. This choice is based on the results obtained from Part 1 of the study; a description of these indices is given in Part 1 (De la Rey, 2008). For the current study the Specific Pollution sensitivity Index (SPI) (Coste in Cemagref, 1982) as well as Biological Diatom Index (BDI) (Lenoir \& Coste, 1996), indices were calculated for the various sampling localities using Omnidia v.3.1 software (Lecointe et al., 1993). The reasons for the selection of these two indices are that SPI has the broadest species base and that BDI showed the best overall correlation to water quality variables in studies performed recently on the Vaal River (Taylor et al., 2007b). More details are given in Part 1 of this paper (De la Rey et al., 2008).

The in-stream habitat was evaluated by means of the Integrated Habitat Assessment version 2 (IHAS) (McMillan, 1998). This evaluation was done for every sampling site on every sampling occasion. IHAS endeavours to numerically express the availability of in-stream habitat in terms of quantity, quality and diversity. In the system both the sampling habitat (stones, vegetation, gravel, sand and mud) and the general river/stream condition is evaluated and a total habitat score calculated.

As diatoms were only sampled from the "Stones in Current" biotope, the SASS biotopes (Stones in Current and Stones out of Current, Marginal- and Submerged Vegetation as well as Gravel
Sand and Mud) were also scored individually to facilitate comparability of the responses of the indices to habitat and water quality variables. It is a well known fact that macroinvertebrates are influenced by habitat availability (Ollis et al., 2006; McMillan, 1998; Dallas, 1997; Karr and Dudley, 1981). Due to this fact, IHAS is mainly used in this study to facilitate interpretation of macroinvertebrate-based data as compared to diatom-based data, rather than as a definitive measure of stream quality. This study does therefore not directly focus on the reliability of IHAS as an indicator of habitat conditions influencing invertebrates.

\section{Water quality}

For details on the water quality analysis for the study please refer to Part 1 of the paper (De la Rey, 2008).

\section{Statistics}

Details on the methods used for the statistical analysis of the data are given in Part 1 of the study (De la Rey, 2008). However, it was felt that an abbreviated overview is justifiable due to minor alterations in statistical methods applied in Part 1.

Again, multiple regressions and correlation analysis were performed using the STATISTICA software package (Release 7, Stat Soft. Inc., United States of America), while Principle Component Analysis (PCA) was performed using CANOCO for Windows (Version 4.51, Biometris-Plant Research International, The Netherlands). Before analysis, all the data were standardised. For the purpose of the multiple regressions the Electrical Conductivity and Total Alkalinity were left out of the analysis as these variables contributed to multi-colinearity in the data. In addition to the above analysis, predicted vs. observed graphs of certain regression analysis are also shown. Such graphs were obtained from the STATISTICA software package.

Another set of multiple regressions was performed to investigate whether season has an influence on the performance of the different indicators used. Season is a categorical dependant variable and was transformed into multiple (dummy-) coded dependant variables (see Hair et al., 1998) for the analysis. In the current study, direct comparison of seasonal response of the bio-indicators was prevented because data from all four sampling periods could only be obtained for 17 of the sites. This was mainly due to varying flow at the identified sites in the different seasons which hindered SASS 5 sampling in many instances. It was therefore deemed preferable to include season as variable in the multiple regression of the combined data set.

\section{Results and discussion}

The results are presented and discussed in three sections. Firstly the correlations between the different bio-indicators will be investigated. This was done to establish whether there is any value in using more than one bioindicator. High correlation between the indicators will show that they respond in a similar fashion to environmental variables, showing that little additional information can be obtained from the extra effort, time and money spent in acquiring the data for the additional indicator. This section will also be used to determine whether bio-indicators sampled from the same biotope are more alike in response to water quality and habitat quality than bio-indicators from other biotopes.

The second section examines the correlation of the biological indices to specific components of water quality in order to ascertain whether the tested bio-indicators respond differently 
to water quality variables. Whereas the previous section focused on whether the bio-indicators are correlated with one another, the focus in this section is therefore rather which water quality and habitat variables influence specific bio-indicators.

Section three entails exploration of the response of bio-indicators to water quality and habitat data by means of multiple regressions. This enables quantification of the influence of water quality and habitat on the different bio-indicators.

\section{Correlation between different bio-indicators}

Table 1 shows the correlation of the different bio-indicators between one another. The correlations between SASS 5 and the number of (invertebrate) taxa with the diatom-based indices (BDI and SPI) are reasonably high at $62 \%$ and $66 \%$ respectively. From the three invertebrate indices calculated according to the SASS 5 protocol, the ASPT displays the highest correlation with the diatom indices at approximately $70 \%$ correlation. The SASS 5 score exhibited slightly lower correlations with the diatom indices than the ASPT, while the number of taxa displayed the lowest correlation with the diatom-based indices.

An analysis was also performed to compare the macroinvertebrate index scores for the different biotopes mentioned in the SASS 5 protocol. When comparing the scores generated from the individual biotopes ( $\mathrm{S}$ - stones in current biotope, $\mathrm{V}$ - vegetation biotope and GSM - gravel sand and mud biotope) with the diatom-based indices, there was little difference in the correlation values. The stones in current biotope, however, did show a slightly higher correlation with diatom-based indices than the other two biotopes. However, the total SASS scores still showed a higher correlation with the diatom indices than any of the individual biotopes.

Although there is a fairly high correlation between the diatom-based indices and the invertebrate-based indices (62\% to $71 \%$; Table 1), there is still a significant amount of difference in the response of the indices to changes in their environment (29\% to $38 \%$; Table 1). It is therefore useful to further investigate the relationships of the different indices to individual components of their environment (for instance water quality and habitat). This is explored in the following sections.

\section{Correlation of bio-indicators with water quality and habitat variables}

The correlation of biological indicators with various water quality variables and habitat (IHAS) is presented in Table 2. From the table it is clear that all the bio-indicators (invertebrate-based as well as diatom-based) correlate well with water quality and habitat variables. The water quality variables that show the lower correlation with the bio-indicators (diatom-based and SASS 5) are $\mathrm{pH}$, dissolved oxygen and water temperature. In general, it is also of interest that diatom indices display a stronger correlation

\begin{tabular}{|l|c|c|}
\hline \multicolumn{3}{|c|}{ TABLE 1 } \\
$\begin{array}{c}\text { Significant correlation between } \\
\text { different bioindicators. Correlations } \\
\text { are significant at } \mathbf{p}<\mathbf{0 . 0 5} \text {. } \mathbf{= 1 0 2}\end{array}$ \\
\hline & SPI & BDI \\
\hline SASS 5 & 0.66 & 0.62 \\
\hline ASPT & 0.71 & 0.69 \\
\hline No. of Taxa & 0.65 & 0.63 \\
\hline SASS (S) & 0.63 & 0.59 \\
\hline ASPT (S) & 0.79 & 0.76 \\
\hline No. Taxa (S) & 0.60 & 0.57 \\
\hline SASS (V) & 0.56 & 0.56 \\
\hline ASPT (V) & 0.73 & 0.72 \\
\hline No. Taxa (V) & 0.48 & 0.49 \\
\hline SASS (GSM) & 0.57 & 0.54 \\
\hline ASPT (GSM) & 0.76 & 0.73 \\
\hline No. Taxa (GSM) & 0.53 & 0.52 \\
\hline (S) Stone biotope; (V) Vegetation biotope; \\
(GSM) Gravel, Sand and Mud biotope \\
\hline
\end{tabular}

\begin{tabular}{|c|c|c|c|c|c|c|c|c|c|c|c|c|c|c|}
\hline \multicolumn{15}{|c|}{$\begin{array}{l}\text { TABLE } 2 \\
\text { Correlation of bioindicators with water quality and habitat variables. } \\
\text { Shaded correlations are significant at } \mathrm{p}<0.05 . \mathrm{N}=102\end{array}$} \\
\hline & $\begin{array}{c}\text { SASS } \\
5\end{array}$ & ASPT & $\begin{array}{c}\text { No. of } \\
\text { Taxa }\end{array}$ & $\begin{array}{l}\text { SASS } \\
\text { (S) }\end{array}$ & $\begin{array}{l}\text { ASPT } \\
\text { (S) }\end{array}$ & $\begin{array}{l}\text { No. } \\
\text { Taxa } \\
\text { (S) }\end{array}$ & $\begin{array}{l}\text { SASS } \\
\text { (V) }\end{array}$ & $\begin{array}{l}\text { ASPT } \\
\text { (V) }\end{array}$ & $\begin{array}{c}\text { No. } \\
\text { Taxa } \\
\text { (V) }\end{array}$ & \begin{tabular}{l|} 
SASS \\
(GSM)
\end{tabular} & \begin{tabular}{|l|} 
ASPT \\
(GSM)
\end{tabular} & $\begin{array}{l}\text { No. } \\
\text { Taxa } \\
\text { (GSM) }\end{array}$ & SPI & BDI \\
\hline $\mathrm{Ca}(\mathrm{mg} / \ell \mathrm{Ca})$ & -0.28 & -0.41 & -0.28 & -0.26 & -0.47 & -0.25 & -0.28 & -0.33 & -0.28 & 0.23 & -0.44 & -0.23 & -0.46 & -0.57 \\
\hline $\mathrm{Cl}(\mathrm{mg} / \ell \mathrm{Cl})$ & -0.51 & -0.53 & -0.53 & -0.47 & -0.58 & -0.46 & -0.46 & -0.54 & -0.43 & -0.45 & -0.60 & -0.45 & -0.73 & -0.75 \\
\hline EC (mS/cm) & -0.43 & -0.54 & -0.42 & -0.40 & -0.61 & $\begin{array}{l}-0.38 \\
\end{array}$ & -0.39 & -0.47 & -0.37 & -0.36 & -0.59 & -0.33 & -0.65 & -0.74 \\
\hline $\mathrm{F}(\mathrm{mg} / \ell \mathrm{F})$ & -0.25 & -0.29 & -0.17 & -0.26 & -0.37 & -0.18 & -0.19 & -0.22 & -0.14 & -0.16 & -0.33 & -0.07 & -0.34 & -0.39 \\
\hline $\bar{K}(\mathrm{mg} / \ell \mathrm{K})$ & -0.47 & -0.51 & -0.44 & -0.45 & -0.55 & -0.40 & -0.38 & $\begin{array}{l}-0.49 \\
\end{array}$ & -0.31 & -0.38 & -0.54 & -0.33 & -0.62 & -0.63 \\
\hline $\mathrm{Mg}(\mathrm{mg} / \ell \mathrm{Mg})$ & -0.39 & -0.50 & -0.37 & -0.38 & -0.57 & -0.33 & -0.36 & -0.40 & -0.33 & -0.32 & -0.53 & -0.28 & -0.54 & -0.62 \\
\hline $\mathrm{NH}_{4}\left(\mathrm{mg} / \ell \mathrm{NH}_{4}-\mathrm{N}\right)$ & -0.37 & -0.43 & -0.41 & -0.36 & -0.51 & -0.38 & -0.33 & -0.45 & -0.31 & -0.35 & -0.49 & -0.38 & -0.58 & -0.59 \\
\hline $\mathrm{NO}_{3}+\mathrm{NO}_{2}\left(\mathrm{mg} / \mathrm{\ell} \mathrm{NO}_{3}+\mathrm{NO}_{2}-\mathrm{N}\right)$ & -0.37 & -0.45 & -0.41 & -0.33 & -0.45 & -0.34 & -0.34 & -0.45 & -0.35 & -0.33 & -0.49 & -0.36 & -0.47 & -0.47 \\
\hline $\mathrm{Na}(\mathrm{mg} / \ell \mathrm{Na})$ & -0.54 & -0.57 & -0.55 & -0.51 & -0.62 & -0.50 & -0.48 & -0.56 & -0.44 & -0.46 & -0.63 & -0.46 & -0.77 & -0.78 \\
\hline $\mathrm{PO}_{4}-\mathrm{P}\left(\mathrm{mg} / \ell \mathrm{PO}_{4}-\mathrm{P}\right)$ & -0.36 & -0.41 & -0.40 & -0.33 & -0.44 & -0.35 & -0.33 & -0.43 & -0.32 & -0.34 & -0.48 & -0.38 & -0.50 & -0.51 \\
\hline $\mathrm{SO}_{4}\left(\mathrm{mg} / \ell \mathrm{SO}_{4}\right)$ & -0.44 & -0.47 & -0.40 & -0.41 & -0.51 & -0.36 & -0.41 & -0.42 & -0.38 & -0.38 & -0.49 & -0.34 & -0.45 & -0.50 \\
\hline $\mathrm{Si}(\mathrm{mg} / \ell \mathrm{Si})$ & -0.25 & -0.36 & -0.28 & -0.24 & -0.44 & -0.25 & -0.24 & -0.35 & -0.24 & -0.21 & -0.42 & -0.22 & -0.44 & -0.47 \\
\hline 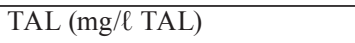 & -0.34 & -0.47 & -0.33 & -0.33 & -0.55 & -0.30 & -0.32 & -0.38 & -0.30 & -0.28 & -0.51 & -0.25 & -0.53 & -0.64 \\
\hline $\mathrm{pH}$ & 0.09 & 0.08 & 0.08 & 0.06 & 0.12 & 0.02 & 0.06 & 0.18 & 0.02 & 0.13 & 0.15 & 0.12 & 0.09 & -0.06 \\
\hline 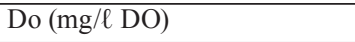 & 0.15 & 0.21 & 0.13 & 0.10 & 0.33 & 0.05 & 0.17 & 0.25 & 0.14 & 0.17 & 0.28 & 0.17 & 0.30 & 0.28 \\
\hline Temp $\left({ }^{\circ} \mathrm{C}\right)$ & 0.11 & 0.09 & 0.16 & 0.12 & -0.08 & 0.19 & 0.13 & 0.02 & 0.18 & 0.15 & 0.01 & 0.18 & -0.13 & -0.11 \\
\hline Turbidity (NTU) & -0.36 & -0.25 & -0.36 & -0.37 & -0.29 & -0.35 & -0.32 & -0.27 & -0.29 & -0.27 & -0.29 & -0.25 & -0.36 & -0.32 \\
\hline IHAS (\%) & 0.60 & 0.40 & 0.61 & 0.61 & 0.40 & 0.59 & 0.57 & 0.44 & 0.53 & 0.50 & 0.39 & 0.50 & 0.31 & 0.27 \\
\hline
\end{tabular}


to almost all water quality variables than do the invertebrate indices. The water quality variables which display the highest correlation to the diatom-based indices are variables reflecting the salinity of the water like $\mathrm{Na}, \mathrm{Cl}$ and $\mathrm{EC}$. Note that in Part I (De la Rey, 2008), Na and Cl were also significant contributors in the regressions of water quality with SPI and BDI, but not in the regressions of water quality with species diversity and evenness. This is probably due to the weak regression results (low $\mathrm{R}^{2}$ values) found for species diversity and evenness. The highest correlation of SASS with water quality variables is also with the ionic components of water quality such as $\mathrm{Cl}, \mathrm{EC}, \mathrm{SO}_{4}$ and $\mathrm{Na}$. This may be because the sampling area is dominated by agricultural activities which may lead to changes in salinity and this may in turn be the dominating determinant of water quality.

SASS indices display a higher correlation to the IHAS index than the diatombased indices. This correlation is as high as $60 \%$ in the case of the SASS 5 score, while the correlation of IHAS and diatom indices is about $30 \%$. It is interesting to note that the ASPT showed slightly better correlations with water quality variables and a lower correlation with IHAS. Table 1 also shows that ASPT is more closely correlated with the diatom-based indices than the SASS5 score or the Number of Taxa. This shows that the ASPT score is more likely to be influenced by water quality than habitat availability. This finding corresponds with the findings of Dallas (1997) who states that the ASPT score is relatively constant between biotopes, suggesting that sites that have different biotopes and habitats available for habitation by aquatic fauna can be compared on the basis of ASPT so that the extent of the impairment of the water quality can be established.

In their evaluation of the relationship of IHAS with SASS, Ollis et al. (2006) suggested that the results obtained showed weak correlation between the two indices. This statement was mainly based on the results obtained from SASS 4 and IHAS scores. The study did however show strong correlations (up to $60 \%$ ) when Total IHAS scores for Mpumalanga and the Western Cape were correlated with SASS 5 scores. This is approximately the same correlation found in the current study (Table 2) which also used SASS 5 as apposed to SASS 4. This correlation however does not indicate cause and effect but merely correlation (Hair et al., 1998). The results from the multiple regression are more indicative of the effect of habitat (as represented by IHAS) on SASS. This evaluation is dealt with in the next section.

\begin{tabular}{|l|l|} 
SASS 5 & W \\
\cline { 2 - 3 } & IH \\
\hline
\end{tabular}

ASPT
TABLE 3

Results for regression performed for bioindicators with (1) habitat and water quality (2) water quality and (3) habitat

\begin{tabular}{|l|l|l|l|}
\hline Dependent & Independent & $\mathbf{R}^{2}$ & Significant contributors
\end{tabular}

variable $\quad$ variables

used

\begin{tabular}{|l|l|l|l|l}
\multirow{3}{*}{ SASS 5} & WQ \& IHAS & 0.651 & IHAS, Na, $\mathrm{SO}_{4}, \mathrm{Cl}, \mathrm{pH}, \mathrm{PO}_{4}, \mathrm{Mg}, \mathrm{F}, \mathrm{K}$ \\
\cline { 2 - 4 } & WQ & 0.491 & $\mathrm{Na}, \mathrm{SO}, \mathrm{pH}, \mathrm{Temp}, \mathrm{Cl}, \mathrm{Turb}$
\end{tabular}

\begin{tabular}{|l|l|l|}
\hline IHAS & 0.365 & IHAS \\
\hline
\end{tabular}

\begin{tabular}{|l|l|l|l|} 
& IHAS & 0.157 & IHAS \\
\hline \multirow{3}{*}{ WQ \& IHAS } & 0.651 & IHAS, Na, Cl, SO, F, Mg \\
\cline { 2 - 4 } & WQ & 0.505 & Na, Temp,
\end{tabular}

\begin{tabular}{l|l|l|l|}
\multirow{3}{*}{ No of Taxa } & WQ & 0.505 & Na, Temp, $\mathrm{pH}, \mathrm{SO}_{4}, \mathrm{Cl}$, Turb, $\mathrm{F}$ \\
\cline { 2 - 4 } & IHAS & 0.367 & IHAS
\end{tabular}

\begin{tabular}{|l|l|l|l|}
\hline \multirow{4}{*}{ SPI } & WQ \& IHAS & 0.799 & $\mathrm{Na}, \mathrm{Si}, \mathrm{pH}, \mathrm{PO}_{4}, \mathrm{Ca}, \mathrm{Cl}$ \\
\cline { 2 - 4 } & WQ & 0.796 & $\mathrm{Na}, \mathrm{Si}, \mathrm{pH}, \mathrm{PO}_{4}, \mathrm{Ca}, \mathrm{Cl}, \mathrm{SO}_{4}$ \\
\cline { 2 - 4 } & IHAS & 0.093 & IHAS \\
\hline \multirow{3}{*}{ BDI } & WQ \& IHAS & 0.813 & $\mathrm{Na}, \mathrm{Si}, \mathrm{NO}_{3}+\mathrm{NO}_{2}, \mathrm{pH}, \mathrm{Ca}, \mathrm{Cl}, \mathrm{PO}_{4}, \mathrm{Mg}$ \\
\cline { 2 - 4 } & WQ & 0.810 & $\mathrm{Na}, \mathrm{Si}, \mathrm{NO}_{3}+\mathrm{NO}_{2}, \mathrm{pH}, \mathrm{Ca}, \mathrm{Cl}, \mathrm{PO}_{4}, \mathrm{Mg}, \mathrm{F}$ \\
\cline { 2 - 4 }
\end{tabular}

\begin{tabular}{|l|l|l|l|} 
& IHAS & 0.071 & IHAS \\
\hline \multirow{3}{*}{ SASS (S) } & WQ \& IHAS & 0.617 & IHAS, Na, Cl \\
\cline { 2 - 4 } & WQ & 0.461 & Temp, Turb, $\mathrm{pH}, \mathrm{SO}_{4}$ \\
\cline { 2 - 4 } & IHAS & 0.371 & IHAS \\
\hline
\end{tabular}

\begin{tabular}{|c|c|c|c|}
\hline SASS (S) & WQ & 0.461 & Temp, Turb, pH, $\mathrm{SO}_{4}$ \\
\hline & IHAS & 0.371 & IHAS \\
\hline & WQ \& IHAS & 0.732 & IHAS, pH, Mg, $\mathrm{PO}_{4}, \mathrm{NH}_{4}$ \\
\hline
\end{tabular}

\begin{tabular}{l|l|l|l|}
\hline & IHAS & 0.163 & IHAS \\
\hline & WQ \& IHAS & 0.578 & IHAS, Na, Temp, Cl
\end{tabular}

\begin{tabular}{|l|l|l|l|}
\multirow{3}{*}{ No of Taxa (S) } & WQ & 0.437 & $\mathrm{Na}, \mathrm{Temp}, \mathrm{Cl}, \mathrm{Turb}, \mathrm{SO}_{4}$ \\
\cline { 2 - 4 } & IHAS & 0.349 & IHAS \\
\hline \multirow{3}{*}{ SASS (V) } & WQ \& IHAS & 0.519 & IHAS, $\mathrm{SO}_{4}, \mathrm{~F}$ \\
\cline { 2 - 4 } & WQ & 0.394 & $\mathrm{Na}, \mathrm{SO}_{4}, \mathrm{Turb}, \mathrm{Cl}$ \\
\hline
\end{tabular}

\begin{tabular}{|l|l|l|l|} 
SASS (V) & WQ & 0.394 & $\mathrm{Na}, \mathrm{SO}_{4}$, Turb, Cl \\
\cline { 2 - 4 } & IHAS & 0.320 & IHAS \\
\hline & WQ \& IHAS & 0.587 & IHAS, $\mathrm{pH}, \mathrm{SO}_{4}, \mathrm{~F}, \mathrm{~K}$ \\
\hline
\end{tabular}

\begin{tabular}{|l|l|l|l|}
\multirow{3}{*}{ ASPT $(\mathrm{V})$} & WQ \& IHAS & 0.587 & $\mathrm{IHAS}, \mathrm{pH}, \mathrm{SO}_{4}, \mathrm{~F}, \mathrm{~K}$ \\
\cline { 2 - 4 } & WQ & 0.551 & $\mathrm{pH}, \mathrm{SO}_{4}, \mathrm{~F}, \mathrm{~K}_{2} \mathrm{PO}_{4}, \mathrm{Si}$ \\
\cline { 2 - 4 } & IHAS & 0.190 & $\mathrm{IHAS}$ \\
\hline
\end{tabular}

\begin{tabular}{|l|l|l|l|}
\multirow{3}{*}{ No of Taxa (V) } & WQ \& IHAS & 0.429 & IHAS, Na \\
\cline { 2 - 4 } & WQ & 0.351 & $\mathrm{Na}, \mathrm{SO}_{4}$, Turb \\
\cline { 2 - 4 } & IHAS & 0.281 & IHAS \\
\hline
\end{tabular}

\begin{tabular}{|l|l|l|l|}
\hline \multirow{3}{*}{ SASS (GSM) } & WQ \& IHAS & 0.470 & IHAS, $\mathrm{pH}, \mathrm{K}$ \\
\cline { 2 - 4 } & WQ & 0.405 & Temp, $\mathrm{pH}, \mathrm{SO}_{4}$ \\
\cline { 2 - 4 } & IHAS & 0.249 & IHAS \\
\hline & WQ \& IHAS & 0.673 & IHAS, $\mathrm{pH}, \mathrm{Mg}, \mathrm{Temp}$ \\
\hline
\end{tabular}

\begin{tabular}{|l|l|l|l|}
\hline \multirow{4}{*}{ ASPT (GSM) } & WQ \& IHAS & 0.673 & IHAS, pH, Mg, Temp \\
\cline { 2 - 4 } & WQ & 0.664 & $\mathrm{Si}, \mathrm{pH}, \mathrm{Mg}, \mathrm{Temp}$ \\
\cline { 2 - 4 } & IHAS & 0.149 & IHAS \\
\hline \multirow{2}{*}{$\begin{array}{l}\text { No of Taxa } \\
(\mathrm{GSM})\end{array}$} & WQ \& IHAS & 0.446 & IHAS, Na, Temp \\
\cline { 2 - 4 } & WQ & 0.365 & $\mathrm{Na}, \mathrm{Temp}, \mathrm{pH}, \mathrm{SO}_{4}$ \\
\cline { 2 - 4 } & IHAS & 0.247 & IHAS \\
\hline
\end{tabular}

Significance chosen at a $p$-value $\leq 0.05$. IHAS denotes habitat scores.

WQ denotes water quality variables.

(S) Stone biotope; (V) Vegetation biotope; (GSM) Gravel, Sand and Mud biotope

\section{Response of bio-indicators to water quality and habitat}

Table 3 presents the multiple regressions performed for each of the indicators with water quality (indicated with WQ in Table 3), habitat (IHAS) as well as a combined multiple regressions for each indicator with both water quality and habitat as 


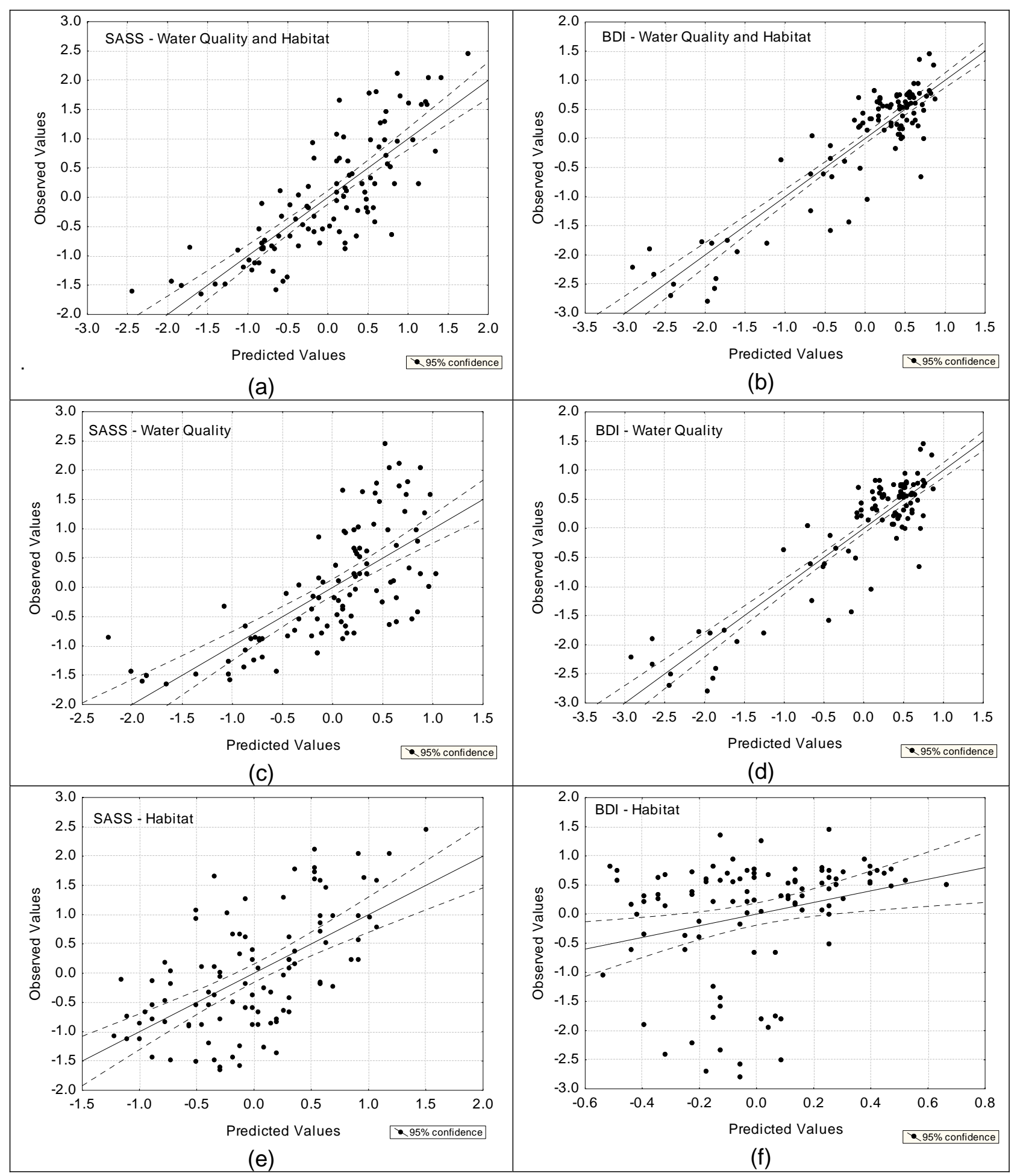

Figure 1

Representation of regression results (predicted against observed graphs) of SASS 5 (left) and BDI (right) using water quality and habitat (top), only water quality (middle) and only habitat (bottom) as independent variables

predictors. Multiple regressions were also performed for the different biotopes (S, V and GSM) that make up the SASS 5, ASPT and number of taxa scores.

From Table 3 one may observe that the habitat score (IHAS) influences SASS 5, ASPT and number of taxa more strongly than the diatom-based indices (SPI and BDI). Only 6 to $8 \%$ of the variance explained by the multiple regression for diatom-based indices could be attributed to IHAS, whereas habitat explained
$35 \%$ of the variance in the SASS 5 and the number of taxa, and $15 \%$ to the ASPT score. This is a much lower value than the $60 \%$ found in the correlation results (Table 2). The apparently conflicting results can be explained by the fact that, in many instances, lower IHAS scores correspond with sites that also displayed poorer water quality in terms of the measured variables. This will have the effect that the correlation values will be higher but does not necessarily reflect causality. The results from 
the multiple regression on the other hand do indicate a 'cause and effect' relationship between IHAS and SASS scores. In the current data set therefore, water quality contributes to approximately $50 \%$ of the variation in the SASS score, while the habitat as reflected/indicated by IHAS contributes approximately $36 \%$.

These above-mentioned results are illustrated in Fig. 1. From the results indicated in Table 2 as well as Figure 1 it is clear that there is little difference in the predictive power of the linear model for the BDI index if water quality alone is used, or when habitat and water quality are used as independent variables (panels $b$ and d) due to the similarity of the $R^{2}$ values and the similarity of the graphs. It is also clear from the graphs that habitat has better predictive power when used for SASS 5 than for BDI (panels e and f).

Table 3 also shows that the chemical variables that influenced the diatom-based indices were $\mathrm{Na}, \mathrm{Si}, \mathrm{pH}, \mathrm{PO}_{4} \mathrm{Cl}, \mathrm{Ca}$, $\mathrm{NO}_{3}+\mathrm{NO}_{2}, \mathrm{Mg}, \mathrm{F}$ and $\mathrm{SO}_{4}$. Overall, chemical variables in water influenced the diatom indices more strongly than was the case for the invertebrate indices, while the habitat seemed to exert little influence on the diatom index scores in the combined analysis $\left(R^{2}=0.071\right.$ to 0.093$)$. There was very little difference in the amount of variation explained by water quality variables for the SPI and BDI respectively. In both cases about $80 \%$ of the variation in the diatom index scores could be explained by water quality variables. The main difference between the indices (SPI/ $\mathrm{BDI}$ ) is the number of species accommodated in the system. BDI utilises approximately 209 species while the SPI can accommodate a larger number of taxa (approximately 1700 species; Coste in Cemagref, 1982). SPI is very sensitive to changes in water quality and provides high correlations with chemistry (e.g. De la Rey et al., 2004) but it has some disadvantages. SPI is regularly updated to take into account taxonomical research results and it is sometimes unclear which version is used. The list of taxa is also dependent on the skills of the operator, on the flora used, and on the time spent on analysis. Since the BDI index employs only 209 important indicator taxa, it facilitates more rapid identification than the SPI. Problems using the BDI may occur in cases where samples contain dominant diatom species that are not used by the index. However, this was not encountered in the current study.

Although the BDI and SPI responded adequately in the current study, these indices need to be adapted for South African conditions by the addition of endemic species. The groundwork for such an adaptation has been laid by a Water Research Commission (WRC) report (Taylor et al., 2007a) that describes about 400 species dominant in South African rivers along with ecological information and gives an account of some endemic species not included in European indices. Another WRC project is currently in progress, the ultimate goal of which will be to formulate a unique diatom index for South Africa and will include the more common diatom species endemic to South Africa (Taylor, 2006).

The important chemical variables that influenced the invertebrate indices were $\mathrm{Na}, \mathrm{Cl}, \mathrm{SO}_{4}, \mathrm{Mg}, \mathrm{F}$ and $\mathrm{K}$ (Table 3). The temperature of the water also significantly influenced all three of the invertebrate indices.

The ASPT component of the SASS 5 scores (Table 3) showed the strongest response to water quality variables and the weakest response to the habitat scores. Of all the scores generated in the different biotopes, the ASPT in the stones biotope showed the strongest response to water quality and habitat scores in comparison with the other indices and other biotopes. In all biotopes the ASPT was the component of SASS 5 that showed the most reliable response to water quality and habitat variation. This is in agreement with the findings of Dickens and Graham (2002) who stated that the ASPT appears to be a more consistent and repeatable measure of river health.

As can be seen in Table 4, season contributed statistically significantly $(p<0.05)$ to the stepwise multiple regressions of SASS, ASPT as well as number of taxa.

The variation of macroinvertebrate indicator scores over season has been noted in several papers (Maloney and Feminella, 2006; Maul et al., 2004; Townsend et al., 1987). Gratwicke (1999) stated that SASS scores improved with the rainy season (January to March) but deteriorated in the dry season. Dallas (2004) found significant differences in ASPT and No. of Taxa between seasons in the Western Cape, with higher ASPT values recorded in winter and spring, while the number of taxa was higher for summer than winter. The same study did not find any significant differences between SASS, ASPT and No. of Taxa values when compared among seasons when samples from Mpumalanga were analysed. For the current study, no statistically significant differences were recorded between samples from different seasons, although SASS and number of taxa scores were higher in spring and summer than for autumn and winter (analysis not shown). The ASPT values were fairly constant between seasons which are also indicated from the multiple regressions in Table 4. The diatom-based indices (Table 4) were not affected significantly by seasonality and water quality remains the only significant factor influencing variation in these indices.

From the presented data it would seem that both indices perform well as bioindicators in all seasons, although the diatom-

\begin{tabular}{|c|c|c|c|}
\hline \multicolumn{4}{|c|}{$\begin{array}{l}\text { TABLE } 4 \\
\begin{array}{l}\text { Multiple regression results for the tested bioindicators with water quality, } \\
\text { habitat and season* *(season used as a categorical variable) }\end{array}\end{array}$} \\
\hline $\begin{array}{l}\text { Dependent } \\
\text { variable }\end{array}$ & $\begin{array}{l}\text { Independent variables } \\
\text { used }\end{array}$ & $\mathbf{R}^{2}$ & Significant contributors \\
\hline \multirow[t]{2}{*}{ SASS 5} & WQ \& IHAS & 0.651 & IHAS, $\mathrm{Na}, \mathrm{SO}_{4}, \mathrm{Cl}, \mathrm{pH}, \mathrm{PO}_{4}, \mathrm{Mg}, \mathrm{F}, \mathrm{K}$ \\
\hline & WQ \& IHAS \& Season & 0.701 & IHAS, Season, DO, Temp., pH, Mg \\
\hline \multirow[t]{2}{*}{ ASPT } & WQ \& IHAS & 0.623 & IHAS, Mg, pH, Temp., K, F \\
\hline & WQ \& IHAS \& Season & 0.627 & IHAS, Mg, pH, Cl, Temp., Season, K \\
\hline \multirow[t]{2}{*}{ No of Taxa } & WQ \& IHAS & 0.651 & IHAS, $\mathrm{Na}, \mathrm{Cl}, \mathrm{SO}_{4}, \mathrm{~F}, \mathrm{Mg}$ \\
\hline & WQ \& IHAS \& Season & 0.681 & IHAS, Na, Season, Cl, Temp., pH, Mg \\
\hline \multirow[t]{2}{*}{ SPI } & WQ \& IHAS & 0.799 & $\mathrm{Na}, \mathrm{Si}, \mathrm{pH}, \mathrm{PO}_{4}, \mathrm{Ca}, \mathrm{Cl}$ \\
\hline & WQ \& IHAS \& Season & 0.799 & $\mathrm{Na}, \mathrm{Si}, \mathrm{pH}, \mathrm{PO}_{4}, \mathrm{Ca}, \mathrm{Cl}$ \\
\hline \multirow[t]{2}{*}{ BDI } & WQ \& IHAS & 0.813 & $\mathrm{Na}, \mathrm{Si}, \mathrm{NO}_{3}+\mathrm{NO}_{2}, \mathrm{pH}, \mathrm{Ca}, \mathrm{Cl}, \mathrm{PO}_{4}, \mathrm{Mg}$ \\
\hline & WQ \& IHAS \& Season & 0.813 & $\mathrm{Na}, \mathrm{Si}, \mathrm{NO}_{3}+\mathrm{NO}_{2}, \mathrm{pH}, \mathrm{Ca}, \mathrm{Cl}, \mathrm{PO}_{4}, \mathrm{Mg}$ \\
\hline
\end{tabular}


based indices seems to be more stable, in terms of their potential to reflect water quality in rivers, than SASS. This is due to the slight effect of season on SASS scores.

\section{Principle component analysis}

A principle component analysis was performed on the data and the results are presented in Fig. 2 and Table 5. The aim of the analysis was to help contextualise the performance of the two types of indices (macroinvertebrate and diatom-based) in terms of the catchment in which the study was performed.

From the PCA it is clear that the main drivers for water quality in the catchment are sodium and chloride (associated with the first ordination axis), while dissolved oxygen and $\mathrm{pH}$ were the strongest contributors to the second ordination axis. The two main groups in the figure are associated according to geographical occurrence in the catchments. Group 1 in Fig. 2 includes sites associated with the headwaters of the Groot Marico while group 2 represents sites in the different towns as well as sites lower down in the river system. This observation corresponds with the general hypothesis that rivers show a downstream increase in salinity as discussed for example by Pillsbury (1981) for North American rivers.

It is also clear from Fig. 2 that the various indices also responded negatively to $\mathrm{PO}_{4}, \mathrm{NH}_{4}$ and $\mathrm{NO}_{2}+\mathrm{NO}_{3}$ (these elements may indicate organic loading). The IHAS score also responded negatively to these variables and this phenomenon might be explained by increased sedimentation as well as algae growth on rocks that occur in eutrophic river systems. This can have a negative effect on the 'stones in current' and 'stones out of current' biotopes, reducing the surface area of rocks on which macroinvertebrates can colonise, thus reducing the IHAS scores.

Although the different indices seem to react negatively to temperature (Fig. 2), this effect might be due to the fact that the sites showing high levels of $\mathrm{PO}_{4}, \mathrm{NH}_{4}$ and $\mathrm{NO}_{2}+\mathrm{NO}_{3}$, represents sites with shallower water levels as the rivers at these sites run through the towns of Mafikeng and Zeerust (see Fig. 1 in Part 1 (De la Rey (2008)). The temperature effect is therefore not to be mistaken for a seasonal effect on the indices. Such an explanation of the data concurs with the results from the regression analysis (Table 4) indicating a low level of influence of season on the various indices.

Interestingly, all of the biological indices respond in a similar fashion to the chemical variables in the water suggesting that both types of indices respond to the main water quality drivers in a given system, corresponding with the results from the correlation analysis in Table 2 . However, due to the longer vectors of the diatom-based indices, we can also conclude from the figure they are more strongly influenced by water quality than the macroinvertebrate-based indices. This is in agreement with the results from the multiple regression analysis in the previous section.

This finding may however not necessarily indicate that diatoms are more sensitive to changes in water quality than macroinvertebrates, but may also reflect on the way in which the index is calculated. The diatom based indices as used in the current study are a reflection of the relative abundance of species found at a particular site, while the macroinvertebrate scores mainly utilise presence and absence to calculate the SASS 5 scores. Since the presence or absence of a single individual in a sample may alter the SASS 5 score, this promotes more variability in the scores than would be true for the diatom based indices. The advantage of a presence/absence type index such as SASS 5 is that analysis is more rapidly obtained than is the case for diatom based indices which utilise relative abundance.

\section{Conclusions}

Both invertebrate- and diatom-based indices showed significant correlations to water quality variables. The different indices

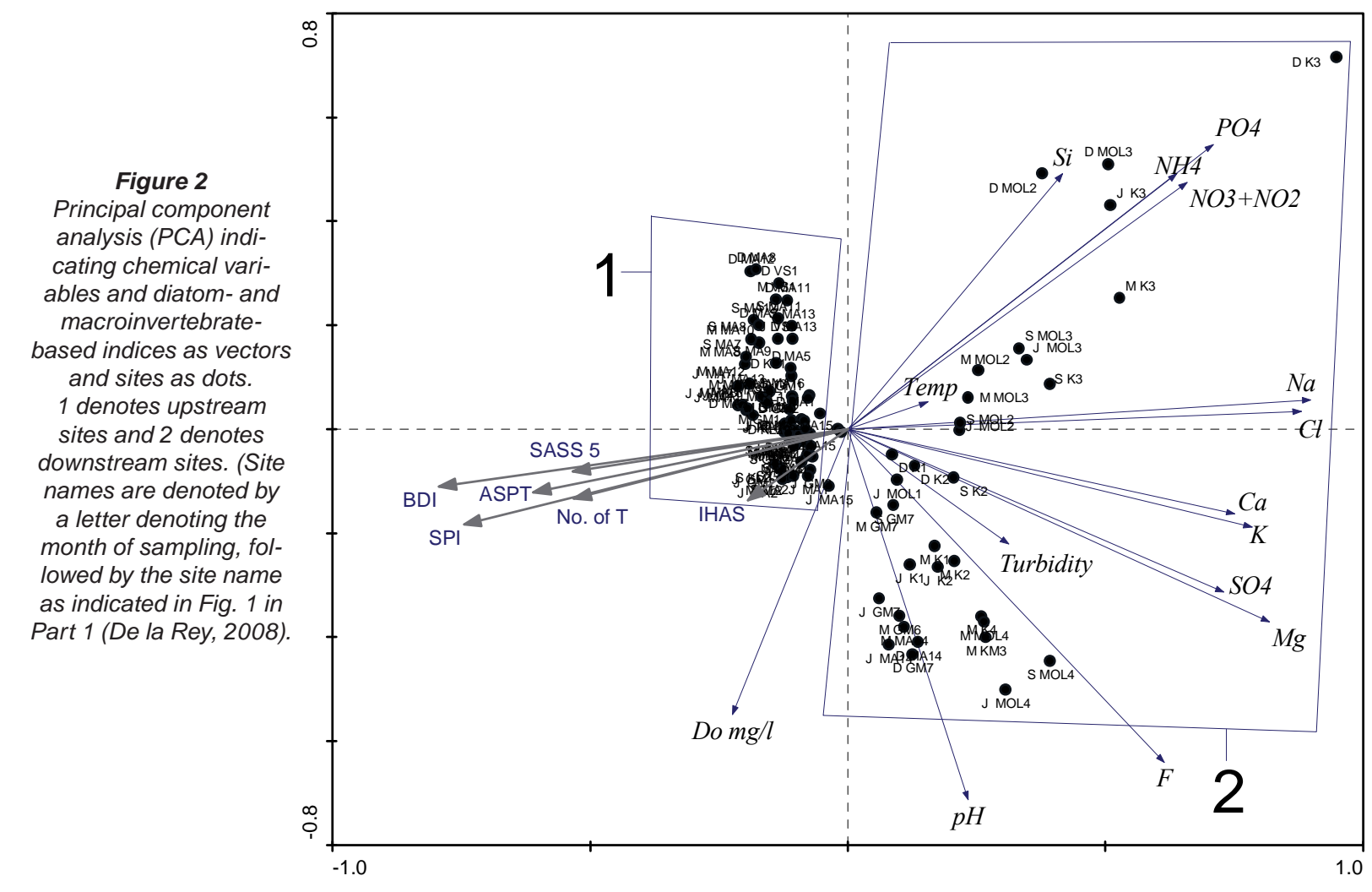




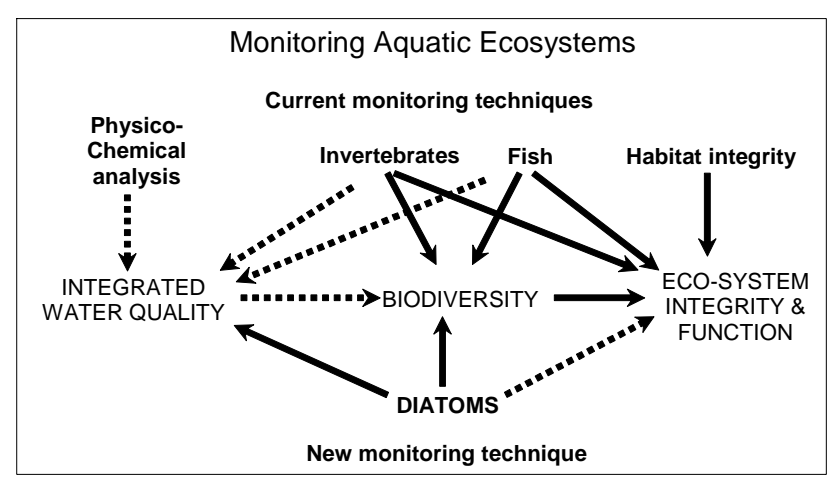

Figure 3

Schematic representation of the relationship between parameters used to monitor the environment and what they indicate. Solid arrows represent a strong relationship while dotted arrows represent a weak relationship (Taylor et al., 2006).

reacted to similar water quality variables, and no conclusions could be made as to which water quality variables most strongly influence diatoms or invertebrates.

The diatom-based indices showed a stronger response to general water quality than did the invertebrate indices and did not respond to changes in season.

The invertebrate indices showed a stronger relationship to changes in habitat scores than did the diatom-based indices. Season also influenced macroinvertebrate indices more than the diatom-based indices, although the total effect of seasonality on the various indices was found to be low.

The ASPT was less influenced by habitat and more by water quality than the other two SASS indices.

This study shows that diatoms can be used to indicate shortto medium-term changes in general water quality that might not be detected when only using invertebrate indices. On the other hand, diatoms are not able to indicate habitat degradation and since this is an important component of the functioning of healthy rivers, invertebrates cannot be excluded from the biomonitoring of rivers and streams.

Figure 3 represents a conceptual model reflecting the positioning of diatoms and SASS 5 as indicators in water resource management.

The concept communicates the relationship between biological indicators and what they may tell us about the environment. Macroinvertebrates, because of habitat affinity, food requirements, reproductive cycles etc. have a stronger relationship to the functioning and the ecological integrity of their direct environment and thus may be used as indicators of these parameters. On the other hand, the diatoms (as micro-organisms and primary producers) are directly influenced by chemical water quality. This is because diatoms need nutrients for growth and reproduction and are physiologically influenced by changes in salinity, pH and other key water quality variables (Taylor et al., 2006).

It is therefore recommended, based on the results of this study that diatoms and SASS 5 can, and should, be used as complementary techniques in the biomonitoring of rivers and streams, in the North-West Province and the entire country.

\section{Acknowledgements}

We gratefully acknowledge the assistance with the identification of certain diatom species by Dr Jonathan Taylor of the School for Environmental Sciences and Development, North- West University; the support with statistical analysis by Mrs Tanja de la Rey of the Centre for Business Mathematics and Informatics, North-West University; as well as the Department of Agriculture, Conservation and Environment for their assistance in the gathering of the data for this article. We would also like to extend our thanks to the Department of Water Affairs and Forestry (DWAF) for the provision of the chemical water quality data used in this study.

\section{References}

ASHTON PJ, PATRICK MJ, MACKAY HM and WEAVER AVB (2005) Integrated biodiversity concepts with good governance to support water resource management in South Africa. Water SA 31 (4) $449-456$

CEMAGREF (1982) Etude Des Méthodes Biologiques Quantitatives D’appréciation De La Qualité Des Eaux. Rapport Division Qualité des Eaux Lyon. Agence financiè de Bassin Rhone-Méditerarée. Corse, Pierre-Bénite. 28 pp.

CHUTTER FM (1998) Research on the Rapid Biological Assessment of Water Quality Impacts in Streams and Rivers. WRC Report No 422/1/98. Water Research Commission. Pretoria, South Africa.

DALLAS HF (1997) A preliminary evaluation of aspects of SASS (South African Scoring System) for the rapid bioassessment of water quality in rivers, with particular reference to the incorporation of SASS in a national biomonitoring programme. S. Afr. J. Aquat. Sci. 23 (1) 79-94.

DALLAS HF (2004) Seasonal variability of macroinvertebrate assemblages in two regions of South Africa: implications for aquatic bioassessment. S. Afr. J. Aquat. Sci. 29 (2) 173-184.

DAVIES B and DAY J (1998) Vanishing Waters. University of Cape Town Press. University of Cape Town. Rondebosch. 487 pp.

DE LA REY PA, TAYLOR JC, LAAS A, VAN RENSBURG L and VOSLOO A (2004) Determining the possible application value of diatoms as indicators of general water quality: A comparison with SASS 5. Water SA 30 (3) 325-332.

DE LA REY PA, VAN RENSBURG L and VOSLOO A (2008) On the use of diatom-based biological monitoring. Part 1: A comparison of the response of diversity and aut-ecological diatom indices to water quality variables in the Marico-Molopo River catchment. Water $S A$ 34 (1) 53-60.

\begin{tabular}{|c|c|c|c|c|c|}
\hline \multicolumn{6}{|c|}{$\begin{array}{c}\text { TABLE } 5 \\
\text { Results for PCA performed for sites in the Marico and Molopo Rivers } \\
\text { (Biological and habitat indices were used as supplementary data in } \\
\text { the ordination) }\end{array}$} \\
\hline Axes & 1 & 2 & 3 & 4 & $\begin{array}{c}\text { Total } \\
\text { variance }\end{array}$ \\
\hline Species-environment correlations & 0.803 & 0.414 & 0.368 & 0.472 & \\
\hline \multicolumn{6}{|l|}{ Cumulative percentage variance: } \\
\hline of species data & 40.6 & 57.8 & 70.5 & 78.8 & \\
\hline of species-environment relation & 75.4 & 83.9 & 88.9 & 94.2 & \\
\hline Sum of all canonical eigenvalues & & & & & 0.347 \\
\hline
\end{tabular}


DICKENS CWS and GRAHAM M (2002) The South African Scoring System (SASS) Version 5: Rapid bio-assessment method for rivers. S. Afr. J. Aquat. Sci. 27 1-10.

EEKHOUT S, BROWN CA and KING JM (1996) National Biomonitoring Programme for Riverine Ecosystems: Technical Considerations and Protocol for the Selection of Reference and Monitoring Sites. NBP Report Series No. 3. Institute for Water Quality Studies, Department of Water Affairs and Forestry, Pretoria.

GRATWICKE B (1999) The effect of season on a biotic water quality index: a case study of the Yellow Jacket and Mazowe Rivers, Zimbabwe. S. Afr. J. Aquat. Sci. 24 (2) 24-35.

HAIR JF (Jr), ANDERSON RE, TATHAM RE and BLACK W (1998) Multivariate Data Analysis. Prentice-Hall, New Jersey. 730 pp.

HARDING WR, ARCHIBALD CGM and TAYLOR JC (2005) The relevance of diatoms for water quality assessment in South Africa: A position paper. Water SA 31 (1) 1- 8.

KARR JR and DUDLEY DR (1981) Ecological perspectives on water quality goals. Environ. Manage. 5 (1) 55-68.

KEMPER NP (2001) RVI: Riparian Vegetation Index. WRC Report No 850/3/01, Water Research Commission, Pretoria, South Africa.

KLEYNHANS CJ (1999) The development of a fish index to assess the biological integrity of South African rivers. Water SA 25 (3) 265270.

KRAMMER K and LANGE-BERTALOT H (1986-1991) Bacillariophyceae. Süßwasserflora von Mitteleuropa 2 (1-4). Spektrum Akademischer Verlag, Heidelberg. Berlin.

LECOINTE C, COSTE M and PRYGIEL, J (1993) “Omnidia”: Software for taxonomy, calculation of diatom indices and inventories management. Hydrobiol. 269/270 509-513.

LENOIR A and COSTE M (1996) Development of a practical diatom index of overall water quality applicable to the French National Water Board network. In: Whitton, BA and E Rott (eds.) Use of Algae for Monitoring Rivers II. Institut für Botanik. Universität Innsbruck. 29-43.

MALONEY KO and FEMINELLA JW (2006) Evaluation of singleand multi-metric benthic macroinvertebrate indicators of catchment disturbance over time at the Fort Benning Military Installation, Georgia, USA Ecological. Ecol. Indic. 6 469-484.

MAUL JD, FARRIS JL, MILAM CD, COOPER CM, TESTA III S and FELDMAN DL (2004) The influence of stream habitat and water quality on macroinvertebrate communities in degraded streams of northwest Mississippi. Hydrobiol. 518 79-94.

McMILLAN PH (1998) An Integrated Habitat Assessment System (IHAS v2), for the Rapid Biological Assessment of Rivers and
Streams. A CSIR research project, Number ENV-P-I 98132 for the Water Resources Management Programme, CSIR.

OLLIS DJ, BOUCHER C, DALLAS HF and ESLER K (2006) Preliminary testing of the integrated habitat assessment system (IHAS) for aquatic macroinvertebrates. S. Afr. J. Aquat. Sci. 31 (1) 1-14.

PILLSBURY AF (1981) The salinity of rivers. Sci. Am. 245 (1) 54-65.

RIVER HEALTH PROGRAMME (2005) State-of-Rivers Report: Monitoring and Managing the Ecological State of Rivers in the Crocodile (West) Marico Water Management Area. Department of Environmental Affairs and Tourism, Pretoria, South Africa. 29 pp.

ROUX DJ (1997) National Aquatic Ecosystem Biomonitoring Programme: Overview of the Design Process and Guidelines for Implementation. NAEBP Report Series No. 6. Institute for Water Quality Studies, Department of Water Affairs and Forestry, Pretoria, South Africa.

TAYLOR JC (2006) Personal communication. School for Environmental Sciences and Development, North-West University, South Africa. 3 August 2006.

TAYLOR JC, DE LA REY PA and VAN RENSBURG L (2005) Recommendations for the collection, preparation and enumeration of diatoms from riverine habitats for water quality monitoring in South Africa. S. Afr. J. Aquat. Sci. 30 (1) 65-75.

TAYLOR JC, HARDING WR and ARCHIBALD CGM (2007a) An Illustrated Guide to Some Common Diatom Species from South Africa. WRC Report No TT 282/07. Water Research Commission. Pretoria, South Africa.

TAYLOR JC, JANSE VAN VUUREN MS and PIETERSE AJH (2007b) The application and testing of diatom-based indices in the Vaal and Wilge Rivers, South Africa. Water SA 33 (1) 51-60.

TAYLOR JC, KRIEL GP and VAN RENSBURG L (2006) The Use of Diatoms for Monitoring Water Quality in Urban Streams. Unpublished report, submitted to Gauteng Nature Conservation July 2006.

TAYLOR JC, PRYGIEL J, VOSLOO A and DE LA REY PA (2007c) Can diatom-based pollution indices be used for biomonitoring in South Africa? A case study of the Crocodile West and Marico water management area. Hydrobiol. 592 455-464.

TOWNSEND CR, HILDREW AG and SCHOFIELD K (1987) Persistence of stream invertebrate communities in relation to environmental variability. J. Anim. Ecol. 57 597-613.

WALMSLEY RD (2000) Perspectives on Eutrophication of Surface Waters: Policy/Research Needs in South Africa. WRC Report No KV129/00. Water Research Commission, Pretoria, South Africa. 
Available on website http://www.wrc.org.za ISSN 0378-4738 = Water SA Vol. 34 No. 1 January 2008 ISSN 1816-7950 = Water SA (on-line) 